\title{
Genetic variants in PCSK9 affect the cholesterol level in Japanese
}

Received: 29 September 2003/ Accepted: 17 November 2003/Published online: 15 January 2004

(C) The Japan Society of Human Genetics and Springer-Verlag 2004

\begin{abstract}
Mutations in the proprotein convertase subtilisin/kexin 9 (PCSK9) gene have been reported in affected members of two families with autosomal dominant hypercholesterolemia. To investigate the effects of common variants in PCSK9 on the cholesterol level, we conducted an association study using a large cohort representing the general population in Japan $(n=1,793)$. Direct sequencing in all of the exonic regions identified 21 polymorphisms. After consideration of linkage disequilibrium among these polymorphisms, we selected and genotyped nine polymorphisms by the TaqMan method. The intron $1 / \mathrm{C}(-161) \mathrm{T}$ and exon $9 / \mathrm{I} 474 \mathrm{~V}$ polymorphisms were associated with levels of total cholesterol (TC) [C(-161)T, $P=0.0285$; I474 V, $P=0.0069$ ] and low-density lipoprotein cholesterol (LDL-C) [C(-161)T, $P=0.0257$; I474 V, $P=0.0007]$. The distributions of these polymorphisms in subjects with miocardial infarction (MI) $(n=649)$ were not different from those in the control population. These results provide
\end{abstract}

K. Shioji $\cdot$ N. Iwai $(\bowtie)$

Department of Epidemiology,

Research Institute,

National Cardiovascular Center,

5-7-1 Fujishirodai, Suita,

Osaka 565-8565, Japan

E-mail: niwai@res.ncvc.go.jp

Tel.: + 81-6-68335012

Fax: + 81-6-68722088

K. Shioji

The Organization for Pharmaceutical

Safety and Research of Japan,

Tokyo, Japan

T. Mannami $\cdot$ Y. Kokubo $\cdot$ N. Inamoto

Department of Preventive Cardiology,

National Cardiovascular Center,

Osaka, Japan

S. Takagi $\cdot$ Y. Goto $\cdot$ H. Nonogi

Division of Cardiology,

National Cardiovascular Center,

Osaka, Japan the first evidence that common variants intron $1 / \mathrm{C}(-161) \mathrm{T}$ and exon 9/I474 V in PCSK9 significantly affect TC and LDL-C levels in the general population in Japan.

Keywords PCSK9 $\cdot$ Cholesterol · Myocardial infarction $\cdot$ Polymorphisms $\cdot$ Association study

\section{Introduction}

Proprotein convertase subtilisin/kexin 9 (PCSK9) in chromosome 1p34.1-p32 is a proprotein convertase that belongs to the subtilase subfamily (Seidah et al. 2003). A related protein is the subtilisin/kexin isoenzyme-1/site-1 protease, which plays a key role in cholesterol homeostasis by processing sterol regulatory element-binding protein (SREBP) (Brown and Goldstein 1999). The expression of PCSK9 mRNA has been reported to be down regulated by dietary cholesterol in C57BL/6 mice and to be up regulated in SREBP transgenic mice (Maxwell et al. 2003). Mutations in PCSK9 have been reported in affected members of two families with autosomal dominant hypercholesterolemia (OMIM 603776) (Abifadel et al. 2003). These observations indicate that PCSK9 plays an important role in cholesterol metabolism. Thus, it is possible that common genetic variations in PCSK9 might affect the cholesterol level in the general population.

To investigate the effects of common variants in PCSK9 on cholesterol level, we detected common variants in PCSK 9 by sequencing and conducted an association study using a large cohort representing the general population in Japan. We found that two polymorphisms, intron $1 / \mathrm{C}(-161) \mathrm{T}$ and exon $9 / \mathrm{I} 474 \mathrm{~V}$, were associated with levels of total cholesterol (TC) and low-density lipoprotein cholesterol (LDL-C). We next investigated the association between these polymorphisms and the incidence of myocardial infarction (MI). 


\section{Subjects and Methods}

Subjects

1. The Suita population: Selection criteria and design of the Suita Study have been described previously (Shioji et al. 2004, in press; Mannami et al. 1997). The sample consisted of 14,200 men and women aged 30-79 years, stratified by gender and 10-year age groups, who were selected randomly from the municipal population registry. They were all invited by letter to attend regular cycles of follow-up examinations (every 2 years). The basic population sampling started in 1989 with a cohort study base, and $51.7 \%(n=7,347)$ of the subjects responded to the invitation letter and had paid their initial visit to the National Cardiovascular Center by February 1997. The participants visited the center every 2 years for regular health checkups. DNA from leukocytes was initially collected from participants who visited the center between May 1996 and February 1998. In the present study, the genotypes were determined in 1,880 consecutive subjects who visited the center between April 2002 and February $2003(n=1,880$, Table 1). Subjects with ischemic heart disease were excluded.

2. The MI group: Selection criteria and design of the MI group have been described previously (Takagi et al. 2002). This group consisted of 649 patients with MI (553 men and 96 women) who were enrolled in the Division of Cardiology at the National Cardiovascular Center between May 2001 and April 2003 (Table 2).

Written informed consent was obtained from each subject after a full explanation of the study, which was approved by the Ethics Committee and the Committee on Genetic Analysis and Genetic Therapy of the National Cardiovascular Center.

Table 1 Suita population characteristics. $B M I$ body mass index, $S B P$ systolic blood pressure, $D B P$ diastolic blood pressure, $P R$ pulse rate, $\% C V A$ percentage of subjects with cerebrovascular accident, $\% O M I$ percentage of subjects with old myocardial infarction, $\% H T$ percentage of subjects with hypertension, $\% D M$ percentage of subjects with diabetes mellitus, $\% H L P$ percentage of subjects with hyperlipidemia, \% drinking percentage of subjects with a drinking habit, \% smoking percentage of subjects with a smoking habit

\begin{tabular}{lccr}
\hline Parameter & Men & Women & $P$ value \\
\hline $\begin{array}{l}\text { Number } \\
\text { Age (years) }\end{array}$ & 867 & 1013 & \\
BMI (kg/m ${ }^{2}$ ) & $66.3 \pm 0.4$ & $63.3 \pm 0.3$ & $<0.0001$ \\
SBP (mmHg) & $23.2 \pm 0.1$ & $22.3 \pm 0.1$ & $<0.0001$ \\
$\begin{array}{l}\text { DBP (mmHg) } \\
\text { PR (beats/min) }\end{array}$ & $79.8 \pm 0.7$ & $128.1 \pm 0.6$ & $<0.0001$ \\
$\begin{array}{l}\text { Total cholesterol } \\
\text { (mmol/l) }\end{array}$ & $56.0 \pm 0.3$ & $76.6 \pm 0.3$ & $<0.0001$ \\
$\begin{array}{l}\text { HDL cholesterol } \\
\text { (mmol/1) }\end{array}$ & $1.43 \pm 0.01$ & $66.0 \pm 0.3$ & 0.9334 \\
$\begin{array}{l}\text { Triglycerides } \\
\text { (mmol/1) }\end{array}$ & $1.38 \pm 0.03$ & $1.68 \pm 0.01$ & $<0.0001$ \\
$\begin{array}{l}\text { Blood glucose } \\
\text { (mmol/l) }\end{array}$ & $5.74 \pm 0.04$ & $1.07 \pm 0.03$ & $<0.0001$ \\
\% CVA & & $5.30 \pm 0.04$ & $<0.0001$ \\
\% OMI & 3.6 & & \\
\% HT & 2.1 & 1.4 & 0.0018 \\
\% DM & 45.9 & 0.5 & 0.0015 \\
\% HLP & 11.4 & 37.2 & $<0.0001$ \\
\% drinking & 14.8 & 4.5 & $<0.0001$ \\
\% smoking & 67.0 & 24.0 & $<0.0001$ \\
\hline
\end{tabular}

$P$ value was calculated by the unpaired $t$-test
Table 2 Miocardial infarction (MI) group characteristics. $B M I$ body mass index, $S B P$ systolic blood pressure, $D B P$ diastolic blood pressure, $P R$ pulse rate, $\% C V A$ percentage of subjects with cerebrovascular accident, $\% O M I$ percentage of subjects with old myocardial infarction, \% $H T$ percentage of subjects with hypertension, $\% D M$ percentage of subjects with diabetes mellitus, $\% L P$ percentage of subjects with hyperlipidemia

\begin{tabular}{|c|c|c|c|}
\hline Parameter & Men & Women & $P$ value \\
\hline Number & 553 & 96 & \\
\hline Age (years) & $61.3 \pm 0.5$ & $64.8 \pm 1.1$ & 0.0028 \\
\hline BMI $\left(\mathrm{kg} / \mathrm{m}^{2}\right)$ & $23.7 \pm 0.1$ & $23.6 \pm 0.3$ & 0.7056 \\
\hline $\begin{array}{l}\text { Total cholesterol } \\
(\mathrm{mmol} / \mathrm{l})\end{array}$ & $5.17 \pm 0.05$ & $5.43 \pm 0.11$ & 0.0400 \\
\hline $\begin{array}{l}\text { HDL cholesterol } \\
(\mathrm{mmol} / \mathrm{l})\end{array}$ & $1.08 \pm 0.02$ & $1.23 \pm 0.04$ & 0.0006 \\
\hline $\begin{array}{l}\text { Triglycerides } \\
(\mathrm{mmol} / \mathrm{l})\end{array}$ & $1.55 \pm 0.04$ & $1.21 \pm 0.09$ & 0.0010 \\
\hline $\begin{array}{l}\text { Blood glucose } \\
(\mathrm{mmol} / \mathrm{l})\end{array}$ & $7.45 \pm 0.67$ & $6.75 \pm 1.59$ & 0.6832 \\
\hline$\% \mathrm{HT}$ & 53.5 & 61.5 & 0.1448 \\
\hline$\% \mathrm{DM}$ & 41.7 & 58.1 & 0.0034 \\
\hline$\%$ HLP & 57.9 & 58.3 & 0.9402 \\
\hline
\end{tabular}

$P$ value was calculated by the unpaired $t$-test

DNA studies

All 12 exonic regions were sequenced for polymorphisms in 48 healthy subjects. Selected polymorphisms were determined by the TaqMan method. Detailed information will be provided upon request.

\section{Statistical analysis}

Values are expressed as mean \pm standard error of the mean (SEM). Since the distribution of triglyceride (TG) values was skewed, a logarithmic transformation was used for the statistical test; however, untransformed means are shown in Tables 1, 2, 5, 6. LDL-C was calculated by Friedewald's formula [(LDL-C) $=($ TC) $-($ HDLcholesterol) - (TG/5). We excluded those whose HDL-cholesterol (HDL-C) or TG levels were $\geq 2.6 \mathrm{mM}$ or $4.53 \mathrm{mM}$ respectively]. All statistical analyses were performed with the JMP statistical package (SAS Institute Inc.). Values of $P<0.05$ were considered to indicate statistical significance. The residuals of lipid levels were calculated by adjusting for gender, age, body mass index (BMI), smoking (cigarettes/day), and consumption of alcohol (ethanol g/week). Data were analyzed using a contingency table analysis and Student's $t$-test. Hardy-Weinberg equilibrium was calculated by a chisquare test. $R$-square values between polymorphisms were analyzed using the SNPAlyze statistical package (Dynacom Inc.).

\section{Results}

Direct sequencing identified 21 polymorphisms (Table 3). We regarded $r-20.5$ as tight linkage (Table 4). Polymorphisms with frequencies of $\leq 0.03$ in the intronic region and 3'-untranslated region were neglected in further analyses. Polymorphisms that were not accompanied by an amino acid change in the exonic regions were also neglected. Accordingly, we selected and genotyped nine polymorphisms for the following association study.

As shown in Table 5, intron $1 / \mathrm{C}(-161) \mathrm{T}$ and exon 9/I474 V polymorphisms were associated with levels of 
Table 3 Polymorphisms and nucleotide sequence in PCSK9

\begin{tabular}{|c|c|c|c|}
\hline Region & Polymorphism & $\begin{array}{l}\text { Allele } \\
\text { frequency }\end{array}$ & Sequence \\
\hline \multirow[t]{4}{*}{ Exon 1} & $\begin{array}{l}\text { C(-64)A } \\
\text { (5'-UTR) }\end{array}$ & 0.13 & CCCACCGCAAGGCTCAAGGCGCCGC[C/A]GGCGTGGACCGCGCACGGCCTCTAG \\
\hline & V4I & 0.01 & СТСТССССТGGCCСТCATGGGCACC[G/A]TCAGCTCCAGGCGGTCCTGGTGGCC \\
\hline & $\begin{array}{l}15-16 \text { ins } \\
(+\mathrm{L})\end{array}$ & 0.13 & GCGGTCCTGGTGGCCGCTGCCACTG[CTG/-]CTGCTGCTGCTGCTGCTGCTCCTGG \\
\hline & A53V & 0.13 & TTGCGTTCCGAGGAGGACGGCCTGG[C/T]CGAAGCACCCGAGCACGGAACCACA \\
\hline Intron 1 & $\mathrm{C}(-161) \mathrm{T}$ & 4 & TAATAATAGTTGGCCTATATGAGTT[C/T]TTTAATTTGCTTTTTGGTCCGCATT \\
\hline Exon 2 & L112L & 0.05 & GCCGGGGATACCTCACCAAGATCCT[G/A]CATGTCTTCCATGGCCTTCTTCCTG \\
\hline Intron 2 & T357C & 0.13 & GCACAGTAACTACTGGCTTTCTGTA[T/C]AAGAATTCCCTTTAAGCCTGGCCATG \\
\hline Intron 3 & $\mathrm{G}(-10) \mathrm{A}$ & 0.04 & САТТСССТССТСТСССАCAAATGTC[G/A]CCTTGGAAAGACGGAGGCAGCCTGG \\
\hline Intron 4 & G-36A & 0.05 & CTGATTTGTTATAGGGTGGAGGGGG[G/A]GTCTTTCTCATGTGGTCCTTGTGTT \\
\hline \multirow[t]{2}{*}{ Exon 6} & Q275Q & 0.01 & GCCTGGAGTTTATTCGGAAAAGCCA[G/A]CTGGTCCAGCCTGTGGGGCCACTGG \\
\hline & P331P & 0.01 & GCСТCTACTCСCCAGCCTCAGCTCC[C/T]GAGGTAGGTGCTGGGGCTGCTGCCC \\
\hline Exon 8 & I424V & 0.01 & GATCCACTTCTCTGCCAAAGATGTC[A/G]TCAATGAGGCCTGGTTCCCTGAGGA \\
\hline \multirow[t]{2}{*}{ Intron 8} & T276C & 0.03 & TCCСTTGTCTGTGTAAGGAGGATGA[T/C]GCCACCTTAAATAGGATTAAATGAG \\
\hline & $\mathrm{T}(-57) \mathrm{C}$ & 0.03 & СТСТССТАССАТGААСТАAАGАTTT[T/C]TGTGGAGGTCСССТСАСТСССАGCА \\
\hline \multirow[t]{2}{*}{ Exon 9} & V460V & 0.03 & GTTGGCAGCTGTTTTGCAGGACTGT[G/A]TGGTCAGCACACTCGGGGCCTACAC \\
\hline & I474V & 0.03 & GGGGCCTACACGGATGGCCACAGCC[A/G]TCGCCCGCTGCGCCCCAGATGAGGA \\
\hline Intron 10 & A241G & 0.11 & СТTТСТССТTATGCACCCACTGCCC[G/A]CGAGGCTTGGTCCTCACAAGTGTGA \\
\hline \multirow[t]{4}{*}{ Exon 12} & $\begin{array}{l}\text { G67A } \\
\text { (3'-UTR) }\end{array}$ & 0.02 & CAGTGCCCTCCCTGGGACCTCCCAC[G/A]TCCTGGGGGCCTACGCCGTAGACAA \\
\hline & $\begin{array}{l}\text { C291T } \\
\text { (3'-UTR) }\end{array}$ & 0.03 & AGCTTTAAAATGGTTCCGACTTGTC[C/T]CTCTCTCAGCCCTCCATGGCCTGGC \\
\hline & $\begin{array}{l}\text { C448T } \\
\text { (3'-UTR) }\end{array}$ & 0.03 & GTGGAGGTGCCAGGAAGCTCCCТCС[C/T]TCACTGTGGGGCATTTCACCATTCA \\
\hline & $\begin{array}{l}\text { T787C } \\
\text { (3'-UTR) }\end{array}$ & 0.07 & TCTAGCCAGAGGCTGGAGACAGGTG[T/C]GCCCCTGGTGGTCACAGGCTGTGCC \\
\hline
\end{tabular}

Bolded polymorphisms were genotyped by the TaqMan method

Allele frequencies described are based on TaqMan data (bolded polymorphisms, the Suita population, 1,793 subjects) or sequence data (48 subjects)

Table 4 Linkage disequilibrium among polymorphisms in PCSK9

\begin{tabular}{|c|c|c|c|c|c|c|c|c|c|c|c|c|c|c|c|c|c|c|c|c|c|}
\hline Polymorphism & 1 & 2 & 3 & 4 & 5 & 6 & 7 & 8 & 9 & 10 & 11 & 12 & 13 & 14 & 15 & 16 & 17 & 18 & 19 & 20 & 21 \\
\hline$C(-64) A$ & 1 & 0.80 & 1.00 & 1.00 & 0.00 & 0.38 & 1.00 & 0.05 & 0.03 & 0.07 & 0.00 & 0.00 & 0.00 & 0.00 & 0.00 & 0.00 & 0.14 & 0.00 & 0.00 & 0.01 & 0.07 \\
\hline V4I & 2 & & 0.80 & 0.80 & 0.00 & 0.40 & 0.80 & 0.00 & 0.00 & 0.07 & 0.00 & 0.00 & 0.00 & 0.00 & 0.00 & 0.00 & 0.20 & 0.00 & 0.02 & 0.00 & 0.20 \\
\hline $\mathrm{A53V}$ & 4 & & & & 0.00 & 0.38 & 1.00 & 0.05 & 0.03 & 0.07 & 0.00 & 0.00 & 0.00 & 0.00 & 0.00 & 0.00 & 0.14 & 0.00 & 0.00 & 0.01 & 0.08 \\
\hline$C(-161) T$ & 5 & & & & & 0.00 & 0.00 & 0.00 & 0.00 & 0.00 & 0.00 & 0.00 & 0.09 & 0.09 & 0.09 & 0.09 & 0.09 & 0.15 & 0.09 & 0.08 & 0.03 \\
\hline $\mathrm{G}(-10) \mathrm{A}$ & 8 & & & & & & & & 0.79 & 0.00 & 0.00 & 0.00 & 0.06 & 0.06 & 0.06 & 0.06 & 0.05 & 0.00 & 0.06 & 0.00 & 0.03 \\
\hline G-36A & 9 & & & & & & & & & 0.00 & 0.00 & 0.00 & 0.04 & 0.04 & 0.04 & 0.04 & 0.03 & 0.00 & 0.04 & 0.00 & 0.01 \\
\hline Q275Q & 10 & & & & & & & & & & 0.00 & 0.00 & 0.00 & 0.00 & 0.00 & 0.00 & 0.00 & 0.00 & 0.00 & 0.00 & 0.00 \\
\hline $\mathrm{P} 331 \mathrm{P}$ & 11 & & & & & & & & & & & 0.00 & 0.00 & 0.00 & 0.00 & 0.00 & 0.00 & 0.00 & 0.00 & 0.00 & 0.00 \\
\hline $\mathrm{I} 424 \mathrm{~V}$ & 12 & & & & & & & & & & & & 0.00 & 0.00 & 0.00 & 0.00 & 0.00 & 0.49 & 0.00 & 0.33 & 0.00 \\
\hline $\mathrm{T} 276 \mathrm{C}$ & 13 & & & & & & & & & & & & & 1.00 & 1.00 & 1.00 & 0.10 & 0.00 & 1.00 & 0.00 & 0.00 \\
\hline $\mathrm{T}(-57) \mathrm{C}$ & 14 & & & & & & & & & & & & & & 1.00 & 1.00 & 0.10 & 0.00 & 1.00 & 0.00 & 0.00 \\
\hline C291T & 19 & & & & & & & & & & & & & & & & & & & 0.00 & 0.00 \\
\hline C448T & 20 & & & & & & & & & & & & & & & & & & & & 0.00 \\
\hline T787C & 21 & & & & & & & & & & & & & & & & & & & & \\
\hline
\end{tabular}

$R^{2}$ values are shown (italics indicates $r^{2}>0.5$ )

Values are based on the genotypes of 48 subjects used for sequence analyses

Bold polymorphisms were selected for genotyping

All values refer to the variant allele indicated in the table 
Table 5 Lipid levels among the PCSK9 polymorphisms (Suita population). $B M I$ body mass index, $T C$ total cholesterol, $H D L-C$ high-density lipoprotein cholesterol. $T G$ triglycerides, $L D L-C$ low- density lipoprotein cholesterol, \% drinking percentage of subjects with a drinking habit, \% smoking percentage of subjects with a smoking habit

\begin{tabular}{|c|c|c|c|c|c|c|}
\hline & \multicolumn{2}{|c|}{ Intron $1 / \mathrm{C}(-161) \mathrm{T}$} & \multirow[t]{2}{*}{$P$ value } & \multicolumn{2}{|c|}{ Exon 9/I474V } & \multirow[t]{2}{*}{$P$ value } \\
\hline & $\mathrm{CC}$ & $\mathrm{CT}+\mathrm{TT}$ & & II & $\mathrm{IV}+\mathrm{VV}$ & \\
\hline Number $(\%)$ & $1,665(92.9)$ & $128(7.1)$ & & $1,704(95.0)$ & $89(5.0)$ & \\
\hline Men/women & $754 / 911$ & $54 / 74$ & & $772 / 932$ & $38 / 51$ & \\
\hline $\operatorname{Age}^{a}$ & $64.4 \pm 0.3$ & $62.8 \pm 1.0$ & 0.1054 & $64.3 \pm 0.3$ & $64.1 \pm 1.2$ & 0.8125 \\
\hline BMI $\left(\mathrm{kg} / \mathrm{m}^{2}\right)^{\mathrm{a}}$ & $22.7 \pm 0.1$ & $22.9 \pm 0.3$ & 0.5178 & $22.8 \pm 0.1$ & $22.5 \pm 0.3$ & 0.4568 \\
\hline $\mathrm{TC}(\mathrm{mM})^{\mathrm{b}}$ & $5.36 \pm 0.02$ & $5.24 \pm 0.08$ & 0.0285 & $5.38 \pm 0.02$ & $5.14 \pm 0.09$ & 0.0069 \\
\hline HDL-C $(\mathrm{mM})^{\mathrm{b}}$ & $1.57 \pm 0.01$ & $1.56 \pm 0.04$ & 0.4431 & $1.56 \pm 0.01$ & $1.63 \pm 0.04$ & 0.1324 \\
\hline $\mathrm{TG}(\mathrm{mM})^{\mathrm{b}}$ & $1.20 \pm 0.02$ & $1.21 \pm 0.08$ & 0.8826 & $1.20 \pm 0.02$ & $1.15 \pm 0.10$ & 0.7617 \\
\hline LDL-C $(\mathrm{mM})^{\mathrm{b}}$ & $3.29 \pm 0.02$ & $3.14 \pm 0.07$ & 0.0257 & $3.29 \pm 0.02$ & $3.01 \pm 0.08$ & 0.0007 \\
\hline$\%$ drinking ${ }^{\mathrm{c}}$ & 46.8 & 45.3 & 0.1238 & 46.8 & 44.9 & 0.7277 \\
\hline Ethanol $(\mathrm{g} / \text { week })^{\mathrm{a}}$ & $75.7 \pm 3.2$ & $86.0 \pm 11.6$ & 0.3953 & $77.4 \pm 3.2$ & $60.6 \pm 14.0$ & 0.2404 \\
\hline$\%$ smoking $^{\mathrm{c}}$ & 17.1 & 22.7 & 0.7472 & 17.4 & 19.1 & 0.6891 \\
\hline Cigarettes (day) ${ }^{\mathrm{a}}$ & $8.3 \pm 0.3$ & $7.5 \pm 1.1$ & 0.5378 & $8.2 \pm 0.3$ & $7.9 \pm 1.4$ & 0.8145 \\
\hline
\end{tabular}

Values are expressed as the mean \pm SEM.

The formula for calculating LDL-C is described in "Subjects and methods"

Student's $t$-test was performed on residual values adjusted for age, gender BMI, smoking (cigarettes/day), and alcohol consumption (ethanol, g/week)

For triglyceride values, although a logarithmic transformation was applied for the statistical test, untransformed values are shown

TC and LDL-C in the Suita population. Since we only found one subject each who was homozygous for minor alleles, these subjects were categorized as heterozygotes. A gender-based subanalysis indicated that the exon $9 /$ I474 V polymorphism significantly influenced the LDL-C level in both male and female subjects (Table 6). TC level in the IV (+VV) genotype of exon 9/I474 V was also lower than that in the II genotype in both male $(P=0.1656)$ and female subjects $(P=0.0133)$. Although $P$-values were not statistically significant, partially due to low statistical power, TC and LDL-C levels in the $\mathrm{CT}(+\mathrm{TT})$ genotype of intron $1 / \mathrm{C}(-161) \mathrm{T}$ were lower
${ }^{a}$ Student's $t$-test was performed

b Subjects receiving hypolipidemic medication were excluded (intron 1/C-161T: CC $n=1512, \mathrm{CT}+\mathrm{TT} n=122$; exon 9/I474 V: $\mathrm{II} n=1,550, \mathrm{IV}+\mathrm{VV} n=83$ )

${ }^{\mathrm{c}}$ Chi-square test was performed

than those in the $\mathrm{CC}$ genotype in both male and female subjects. No significant deviation from Hardy-Weinberg equilibrium was observed in these polymorphisms [C(-161)T: $P=0.8290$, I474 V: $P=0.9971]$.

We next evaluated whether intron $1 / \mathrm{C}(-161) \mathrm{T}$ and exon $9 / \mathrm{I} 474 \mathrm{~V}$ polymorphisms were associated with the incidence of MI. Distribution of these polymorphisms in subjects with MI were no different from those in the Suita population (Table 7). A gender-based subanalysis indicated that these polymorphisms did not influence the incidence of MI in either male or female subjects (data not shown), nor were they associated with lipid levels in

Table 6 Lipid levels among the PCSK9 polymorphisms (gender-based subanalysis). $T C$ total cholesterol, $H D L$ - $C$ high-density lipoprotein cholesterol, $T G$ triglycerides, $L D L-C$ low-density lipoprotein cholesterol

\begin{tabular}{llllll}
\hline & \multicolumn{2}{l}{ Intron 1/C(-161)T } & & Exon 9/I474V \\
\hline Men & CC & CT + TT & $P$ value & II & IV + VV \\
Number (\%) & $742(93.1)$ & $55(6.9)$ & & $757(95.0)$ & $40(5.0)$ \\
TC (mM) & $5.10 \pm 0.03$ & $4.98 \pm 0.10$ & 0.1769 & $5.10 \pm 0.03$ & $4.95 \pm 0.12$ \\
HDL-C (mM) & $1.43 \pm 0.01$ & $1.43 \pm 0.05$ & 0.9723 & $1.42 \pm 0.01$ & $1.45 \pm 0.06$ \\
TG (mM) & $1.36 \pm 0.04$ & $1.43 \pm 0.15$ & 0.9598 & $1.37 \pm 0.04$ & $1.41 \pm 0.17$ \\
LDL-C (mM) & $3.09 \pm 0.03$ & $2.89 \pm 0.09$ & 0.0554 & $3.08 \pm 0.03$ & $2.88 \pm 0.11$ \\
Women & CC & CT & $P$ value & II & 0.1656 \\
Number (\%) & $770(92.0)$ & $67(8.0)$ & & $793(94.9)$ & $43(5.1)$ \\
TC (mM) & $5.58 \pm 0.03$ & $5.40 \pm 0.10$ & 0.1042 & $5.59 \pm 0.03$ & $5.26 \pm 0.12$ \\
HDL-C (mM) & $1.68 \pm 0.01$ & $1.65 \pm 0.05$ & 0.2716 & $1.67 \pm 0.01$ & $1.77 \pm 0.06$ \\
TG (mM) & $1.04 \pm 0.02$ & $1.03 \pm 0.07$ & 0.7957 & $1.05 \pm 0.02$ & $0.91 \pm 0.09$ \\
LDL-C (mM) & $3.44 \pm 0.03$ & $3.30 \pm 0.10$ & 0.1964 & $3.45 \pm 0.03$ & $3.09 \pm 0.12$ \\
\hline
\end{tabular}

Values are expressed as the mean \pm SEM

For triglyceride values, although a logarithmic transformation was The formula for calculating LDL-C is described in "Subjects and methods"

Subjects receiving hypolipidemic medication were excluded

Student's $t$-test was performed on residual values adjusted for age, BMI, smoking (cigarettes/day), and alcohol consumption (ethanol, $\mathrm{g} /$ week) applied for the statistical test, untransformed values are shown in the table 
Table 7 Association between PCSK 9 polymorphisms and the incidence of myocardial infarction (MI)

${ }^{\mathrm{a}}$ Genotype distributions in the Suita population and patients with MI were compared using the chi-square test

\begin{tabular}{lcccccc}
\hline & \multicolumn{2}{l}{ Intron 1/C(-161)T } & & $P$ value & Exon 9/I474V & $P$ value \\
\cline { 2 - 3 } \cline { 5 - 6 } & CC & & II + TT & & IV + VV & \\
\hline $\begin{array}{c}\text { Suita population, } \\
\text { number (\%) }\end{array}$ & $1665(92.9)$ & $128(7.1)$ & & $1704(95.0)$ & $89(5.0)$ & \\
$\begin{array}{c}\text { Patients with MI, } \\
\text { number (\%) }\end{array}$ & $593(92.2)$ & $50(7.8)$ & $0.5943^{\mathrm{a}}$ & $609(95.9)$ & $26(4.1)$ & $0.3684^{\mathrm{a}}$ \\
\hline
\end{tabular}

patients with MI. One possible reason for this lack of association may be that a substantial proportion of the MI group had dyslipidemia and had been treated with hypolipidemic drugs.

\section{Discussion}

While C(-161)T and I474 V polymorphisms have been reported previously (Abifadel et al. 2003), association studies have not been reported. The present study clarified that the $\mathrm{C}(-161) \mathrm{T}$ and $\mathrm{I} 474 \mathrm{~V}$ polymorphisms were significantly associated with TC and LDL-C levels in the total population. Even in a gender-based subanalysis, the I474V polymorphism significantly influenced the LDL-C level in both male and female subjects. It is unclear whether these polymorphisms are functional variations or just in linkage disequilibrium with other important variants, and this question requires further investigation. Since Ile at amino acid number 474 was not conserved in either rats or mice, another polymorphism in tight linkage with I474 V may be influential. In fact, a polymorphism in the polypyrimidine-rich tract in intron 8/T(-57)C was almost completely concordant with I474V $\left(r^{2}=1.00\right.$, Tables 3 and 4$)$.

The minor allele frequencies of intron $1 / \mathrm{C}(-161) \mathrm{T}$ and exon 9/I474 V polymorphisms were low. However, variances between residuals of TC in genotypes [C(-161) T: $\mathrm{CC}$ versus $\mathrm{CT}+\mathrm{TT}$, I474 V: II versus IV+ VV] were similar $[C(-161) \mathrm{T}$ : F-ratio $=0.2368, P=0.6266$; I474 V: F-ratio $=2.418, P=0.1201$ (Levene's test)]. Variances between residuals of LDL-C in the genotypes were also similar $[C(-161) \mathrm{T}$ : $\mathrm{F}$ ratio $=0.1060, P=0.7448 ; \mathrm{I} 474 \mathrm{~V}$ : $\mathrm{F}$ ratio $=0.4436, P=0.5055]$. The sample power was 0.9234 ( $\alpha$-value: 0.05 , sigma: 27.70 , delta: 2.35 , adjusted power: 0.8990 , confidence limit: $0.2978-0.9996)$. Thus, these associations were thought to have adequate statistical power. It has been recommended that a single, nominally significant association should be viewed as tentative until it has been independently replicated at least once and preferably twice (Ioannidis et al. 2001). Accordingly, it will be necessary to verify the association between these PCSK9 polymorphisms and the levels of $\mathrm{TC}$ and LDL-C using a larger number of subjects from the Suita cohort or another population.

We found two polymorphisms that were associated with TC and LDL-C levels among nine polymorphisms of PCSK9 in the Suita population. However, if we apply Bonferroni's correction for multiple tests, only exon 9/I474 V polymorphism can be considered significantly associated with the HDL level [intron $1 / \mathrm{C}(-161) \mathrm{T}$, TC: $P=0.2565$, LDL-C: $P=0.2313$; exon $9 / \mathrm{I} 474 \mathrm{~V}$, TC: $P=0.0621$, LDL-C: $P=0.0063, P$-values are corrected by multiplying by 9 (nine polymorphisms)]. Again, it will be necessary to verify the association between these PCSK9 polymorphisms and the levels of TC and LDL-C using a larger number of subjects from the Suita cohort or another population.

A high LDL-C level is a well-known coronary risk factor (Kannel et al. 1979). Although PCSK9 polymorphisms affected the LDL cholesterol level, they did not affect the incidence of MI. The intron $1 / C(-161) T$ polymorphism was inversely associated with LDL-C level and incidence of MI, although these associations were not significant. This was thought to be due, at least in part, to the low statistical power. A much larger group of MI subjects might be necessary to detect the influence of these variants on the incidence of MI.

In conclusion, the present study provides the first evidence that common variants intron $1 / \mathrm{C}(-161) \mathrm{T}$ and exon $9 / \mathrm{I} 474 \mathrm{~V}$ in PCSK9 significantly affect TC and LDL-C levels in the general Japanese population.

Acknowledgements This study was supported by the Program for the Promotion of Fundamental Studies in Health Science of the Organization for Pharmaceutical Safety and Research of Japan. We are very grateful to Dr. Soichiro Kitamura, President of the National Cardiovascular Center, for his support of our research. We would like to thank Dr. Otosaburo Hishikawa, Dr. Katsuyuki Kawanishi, and Mr. Shigeru Kobayashi for their continuous support of our population survey in Suita City. We also thank the members of the Satsuki-Junyukai.

\section{References}

Abifadel M, Varret M, Rabes JP, Allard D, Ouguerram K, Devillers M, Cruaud C, et al (2003) Mutations in PCSK9 cause autosomal dominant hypercholesterolemia. Nat Genet 34:154 156

Brown MS, Goldstein JL (1999) A proteolytic pathway that controls the cholesterol content of membranes, cells, and blood. Proc Natl Acad Sci USA 96:11041-11048

Ioannidis JPA, Ntzani EE, Trikalinos TA, Contopoulos-Ioannidis DG (2001) Replication validity of genetic association studies. Nat Genet 29:306-309

Kannel WB, Castelli WP, Gordon T (1979) Cholesterol in the prediction of atherosclerotic disease. New perspectives based on the Framingham study. Ann Intern Med 90:85-91

Mannami T, Konishi M, Baba S, Nishi N, Terao A (1997) Prevalence of asymptomatic carotid atherosclerotic lesions detected by high-resolution ultrasonography and its relation to cardiovascular risk factors in the general population of a Japanese city: the Suita study. Stroke 28:518-525 
Maxwell KN, Soccio RE, Duncan EM, Sehayek E, Breslow JL (2003) Novel putative SREBP and LXR target genes identified by microarray analysis in liver of cholesterol-fed mice. J Lipid Res 44(11):2109-2119

Seidah NG, Benjannet S, Wickham L, Marcinkiewicz J, Jasmin SB, Stifani S, Basak A, Prat A, Chretien M (2003) The secretory proprotein convertase neural apoptosis-regulated convertase 1 (NARC-1): liver regeneration and neuronal differentiation. Proc Natl Acad Sci USA 100:928-933

Shioji K, Kokubo Y, Mannami T, Inamoto N, Morisaki H, Mino Y, Tago N, Yasui N, Iwai N (2004) Association between hypertension and the $\alpha$-adducin, $\beta 1$-adrenoreceptor and G-protein $\beta 3$ subunit genes in the Japanese population; The Suita Study. Hypertens Res (in press)

Takagi S, Iwai N, Yamauchi R, Kojima S, Yasuno S, Baba T, Terashima M, Tsutsumi Y, Suzuki S, Morii I, Hanai S, Ono K, Baba S, Tomoike H, Kawamura A, Miyazaki S, Nonogi H, Goto Y (2002) Aldehyde dehydrogenase 2 gene is a risk factor for myocardial infarction in Japanese men. Hypertens Res $25: 677-681$ 